\title{
Editorial: Risk and Risk Management in Management Accounting and Control
}

*Kim Soin and Paul Collier

\begin{abstract}
:
Recent world events, most notably the global financial crisis, have refocused and intensified interest on risk and the nature of systems that operate to manage risk. One area that has received relatively little attention is the interrelation between risk, risk management and management accounting and control practices. This editorial provides an introduction to the special issue of the journal on "Risk and Risk Management in Management Accounting and Control". It argues that risk and the way it is managed has become a feature of organizational life in both the public and private sectors. By changing organizational practices risk management can facilitate and legitimise certain ways of organizing. It has the potential to change lines of responsibility and accountability in organizations, representing a particular way of governing individuals and activities. The argument is further made that risk management has moved away from being an issue of narrow concern to finance (value at risk, derivatives, etc.) or accountants (financial statement disclosure, etc.) to an issue about management control and therefore a key area in which management accountants need to engage. This editorial also highlights the potential side-effects of risk management, including issues around trust and accountability, but also the focus on secondary or defensive risk management and the rise of reputation risk.
\end{abstract}

Key words: Risk Management; management accounting; management control

Acknowledgements: The authors are grateful for the valuable comments and suggestions made by John Burns, David Otley, Robert Scapens and Bob Soin on an earlier version of this essay. We would also like to thank all the reviewers involved in this special issue. This special issue had its origins in the 8th International Management Control Research Conference held at the University of Greenwich in 2010. The authors acknowledge the support of the Management Control Association and its chair Professor Elaine Harris in helping to make this special issue possible.

\section{Affiliation:}

Honorary Professor Paul Collier, School of Accounting, Economics and Finance, Deakin University, 221 Burwood Highway, Burwood VIC 3125 Australia. Email paul.collier@deakin.edu.au

*(Corresponding author) Dr Kim Soin: Associate Professor of Accounting and Management, University of Exeter Business School, Department of Accounting, Streatham Court, Rennes Drive, Exeter, UK. EX4 4PU. Tel: +44 (0) 1392 726689; Email: k.soin@exeter.ac.uk 


\section{Editorial: Risk and Risk Management in Management Accounting and Control}

Risk and the way it is managed has become a feature of organizational life in both the public and private sectors. Since the first Management Accounting Research special issue on risk management was published in 2009, there has been a great deal of attention to risk in academic circles, in industry, in the professions and in the media. Recent world events including the global financial crisis, the financial crisis facing the Eurozone, the horsemeat scandal, the Japanese earthquake and tsunami, the floods in Thailand and the Deepwater Horizon oil spill in the Gulf of Mexico have all refocused and intensified interest in risk, the nature of systems that operate to manage risk and the outcomes of risk management (Scheytt, Soin, Sahlin-Andersson and Power, 2006). This is not to say that the world has got riskier as Beck (1992) suggests - at the end of the day the Chernobyl disaster was worse in terms of human deaths and suffering than Deepwater Horizon - although the long-term ecological and economic consequences are still unknown. Nevertheless, the perception of risk is growing and organizational practices have increasingly become organised around risk. This in part is due to three factors: first, the increased interest in corporate governance and a focus by Boards of Directors on identifying, assessing, treating and monitoring risks as well as evaluating the effectiveness of management controls to manage risk; second, a trend towards world-wide government regulation utilising risk-based regulatory approaches that focus on tighter internal control mechanisms. For example, legislation in the form of the Sarbanes-Oxley Act of 2002 in the US, the UK's Corporate Governance Code (Financial Reporting Council, 2010), the Basle banking accords, the framework implemented by the Committee of Sponsoring Organizations of the Treadway Commission (COSO), and the adoption of ISO31000 as the international risk management standard. Similar frameworks have been created in other countries; third, the media amplification of scandals (Soin and Huber, Forthcoming 2013), although as Kasperson et al. (2003) note, this view should be treated with caution.

These factors suggest that the study of risk and risk management has moved beyond the silos of health and safety, insurance and credit management and the narrow treatments by finance (including calculations of value at risk and the use of derivatives) and by accounting (especially the focus on disclosure in financial statements). The global financial crisis highlighted the weakness of ignoring 'operational risk': the risks arising from the actions of people, systems and processes and a broader appreciation of the external risks facing organisations. The international risk management standard ISO31000 (ISO, 2009) defines risk as the effect of uncertainty on achieving objectives; with risk management being the set of principles, frameworks and processes for managing risk. The movement towards enterprise risk management (ERM) (COSO, 2004) has shifted the focus to a more holistic appreciation of risk. It highlights that appropriate risk-based controls (COSO, 2007) need to be put in place to help ensure, as far as possible, that organizational objectives are achieved. 
This has important implications for management accounting researchers and practitioners, especially those concerned with management control.

The amplified public perception of risk has acted as an evolutionary pressure that has accelerated the development of risk management in organizational settings. In a relatively short space of time there has been something of a revolution in the understanding and practice of risk management (Power, 2007; Power, Scheytt, Soin, \& Sahlin, 2009). Promoted by academic scholars, risk 'experts', professional bodies, consultants, international organizations and regulators - risk, and the way it is managed - has become an increasingly prominent feature of organizations and their environments. From its origins in specialist areas such as occupational health and safety, insurance, and the hedging of financial and credit risks, it has expanded to become a cornerstone of good governance and, through riskbased regulation, it has become a regulatory resource (Ayres and Braithwaite, 1992; McGoun, 1995; Miller, Kurunmäki, \& O'Leary, 2008) in both the private and public sectors.

The failure of many high profile financial institutions has raised widespread concerns about the use of complex financial derivatives in the relentless pursuit of short-term profit. These failures have accentuated the failures of governance and internal control due to excessive risk taking behaviour. The Deepwater Horizon oil spill in the Gulf of Mexico not only resulted in environmental, economic and reputational losses, but also highlights the consequences of poor risk management practices where excessive cost-cutting becomes an organizational priority. By changing organizational practices (for example, through the use of artefacts like risk registers, risk maps and ERM systems), risk management can facilitate and legitimise certain ways of organizing. It has the potential to change lines of responsibility and accountability in organizations, representing a particular way of governing individuals and activities. Similar to Miller's (1994) arguments around accounting systems, risk management systems can:

"transform the formal structures of organizations in line with powerful institutional rules. These rules can then come to be binding on particular organizations. The formal structures of organizations can thus reflect the myths of their institutional environments, rather than the demands of their work activities" (p. 10).

Risk management is not just an important concern to individual organizations it also provides a link between organizations and the environment in which they operate. Financial and environmental disasters affect multiple organizations and whole sections of society. As Power (2004) has argued, "secondary risks to an organization's reputation are becoming as significant as the primary risks for which experts have knowledge and training" (p.14). Risk management is increasingly seen as critical at a cross-organizational level. Indeed, three of the papers in this special issue (Dekker, Sakaguch \& Kawai; Ding, Dekker \& Groot; and Jordan, Jørgensen \& Mitterhofer) focus on inter-firm collaboration through supply chain networks or project management. Risk management is also seen as inseparable from 
broader international issues, as exemplified in the paper by Plesner Rossing on the taxation implications of international transfer pricing.

The manner in which risk management changes organizational and management control practices is quite striking (Huber, 2009). For example, in the UK higher education sector, the Higher Education Funding Council for England (HEFCE) and more recently the Quality Assurance Agency (QAA), have both utilised risk-based regulation as a mode of control for university governance and internal control. Since 2002, HEFCE has imposed prescriptive guidance on UK universities which requires them to implement risk management systems (HEFCE, 2001-28). Universities now have high level risk and audit committees, risk 'champions' and monitoring and control systems that provide oversight of the risk management process - something that was unheard of ten years ago (Power et al., 2009).

In some organizations however, the whole risk management approach can be seen as a 'box ticking' exercise that does not impact on day-to-day organizational processes but merely represents a need for the external display of internal coherence. As with many management systems, opponents see box-ticking as a frequently occurring problem distracting attention from other types of risks (Power, 2007). The assumption in much of the work on governance-led approaches to risk management is that the higher the risk, the greater should be the level of management control, a logical consequence of the cybernetic model of control. However, Berry, Collier, \& Helliar (2005) identified the 'risk of control': as controls become more prescriptive and dependent on the predictive model in use "organizational participants may have less room to manoeuvre, and in a turbulent environment this may result in an increase rather than a decrease in risk" (p.297) due to a lack of flexibility as excessive control leads to opportunities being missed.

This leads us to questions that have been raised about whether organizations - through their choice of technologies, products, processes and globalised locations - have simply become risky by design? How does risk management relate to inter-firm activities and organizations in a network - for example in supply chains? How can organizations (and institutions) be designed to effectively assess, manage and govern risks? What are the organizational side effects of risk management - including the side effects of managing risk itself (Scheytt et al., 2006) and, what is the nature of the relationship between the chief management accountant and the risk function? Under risk-based regulation the use of risk management systems is often a response to limited regulatory resources (Power, 2007). Soin and Huber (Forthcoming 2013) present this argument in the case of UK financial services and the introduction of the risk management systems under the tenure of the Financial Services Authority. Does pressure on reducing costs, for example through increased competition or compliance costs, create new risks (Dunne and Hellier, 2002)?

However, the consequences for management accounting and control systems are not entirely clear. While there has been significant attention in the accounting literature around the financial and technical aspects of risk management (e.g. Crouhy et al., 2000; Langfield- 
Smith, 2008; Stulz, 1996), little attention has been paid to the actual management of risk and the effects of risk management in organizations. Indeed, with a few exceptions (Arena, Arnaboldi, \& Azzone, 2010; Bhimani, 2009; Collier and Berry (2002); Mikes, 2009, 2011; Power et al., 2009; Scheytt, Soin, Sahlin-Andersson, \& Power, 2006; Wahlström, 2009 and Woods (2009), we have relatively little understanding about the (complex) interrelation between risk, risk management and management accounting and control practices. Furthermore, the discourse of risk and the way it is managed is not always a feature of the wider management control framework in organizations. Research by Collier, Berry, \& Burke (2007) identified the marginalisation of management accountants in risk management due to the perceived narrowness of their (accounting) skills base relative to a broader appreciation of organizational risk. The fundamental research question is how management accountants are implicated in risk management, particularly in terms of their understanding of management control and performance measurement which are directed, like risk management, at the achievement of organizational objectives.

This special issue provides a collection of papers which contributes to discussions about the issues raised above and the interrelation between risk management and management accounting and control practices. Despite the variety of papers, one over-arching theme is that risk management has moved away from being seen from the finance silo's view of value at risk and derivatives, and the accounting silo's view of disclosure in financial reports to a central concern with management control. In various ways, the papers deal with several inter-related themes that expand the notion of risk management beyond its current boundaries in the academic literature. Drawing on Miller (2004), the papers here show that risk management "could not, and should not, be studied as an organizational practice in isolation from the wider social and institutional context in which it operates" (p. 9). Indeed, the social construction of risk objects (Hilgartner, 1992), managerial processes and the design of risk governance systems have implications for the practice of management accounting and control.

The first two papers in our collection offer a critique of risk management. Huber \& Scheytt ask why risk management, in the face of its evident failure to manage risks during the global financial crisis, has retained its importance? Building on the work of Power (2007) and Italian social theorist Giorgio Agamben $(1998,2005)$, Huber \& Scheytt show how elites can use management control systems for their own interests. They apply Agamben's notion of a "permanent state of exception" to develop their idea of a dispositif of risk management which reproduces larger societal values and determines organizational responses to the rise of risk management which in turn shapes organizational (im)balances of power. Elites are enabled to take extraordinary measures which cannot be rescinded after the initial state of exception has ended. These measures add to, but also gradually replace, other forms of management control as they turn the exception into an enduring standard, and use fear and anxiety which, in turn, can result in even more calls for risk management. 
Tekathen and Dechow argue against the definition of enterprise risk management (ERM) as a set of activities that lead to organizational alignment and accountability. The authors highlight three insights from their research: First, ERM systems draw out how uncertainty creates organizational space for heterogeneity, potentiality and otherness that is otherwise rendered opaque in daily business operations. Second, ERM processes produce a nearly continuous re-alignment of subjects and objects which effectively become separated from, rather than integrated with each other, making it difficult to manage risks on an enterprisewide basis. Third, ERM allows people to assume stewardship of everything and nothing at the same time, because ERM systems produce awkward, incomplete, yet complex information objects that require users to engage critically with the ways in which risk and chance concurrently produce clarity and opacity. Tekathen and Dechow conclude that these three findings suggest that ERM creates inverse information hierarchies pushing complex, unresolved and abstract information to the top of the organization.

The third and fourth papers in this special issue build on prior research findings in relation to supply chains and draw out the relationship between organizations in a supply chain network connected through risk management.

Dekker, Sakaguch \& Kawai identify the risk exposure emanating from the supply chain and examine the use of control practices to manage risks associated with intensified collaboration with supply chain partners. Dekker et al. highlight the role of perceived goodwill and competence trust as well as management control practices and find that for risky transactions, buyers favour suppliers in whom they place high goodwill trust, while trust in supplier competencies facilitates the use of supply chain management (SCM) practices. However, they also show that the impact of certain transaction characteristics, for example, technological unpredictability, and monitoring problems appear to reduce the ability to place confidence in suppliers' goodwill and limit the use of SCM practices that require more intensive cooperation. Dekker et al. conclude that the implications of risk extend well beyond the contract and influence the broader package of practices used for managing cooperation between firms in a supply chain relationship.

Ding, Dekker \& Groot studied partner selection and formal contracts as key approaches in managing transaction risk in inter-firm relationships. Focusing on partner selection criteria brings in the notion of risk as it enables a more fine-grained analysis of which selection dimension mediates risk on which contract dimensions. Ding et al.'s findings reveal that when facing increasing transaction risk resulting from high task interdependence and a broad transaction scope, firms select their partners by relying on trust-based and reputation-based selection criteria. However, they also use more complex contracts. When the transaction scope is broad and firms have had prior ties with the partner, Ding et al. found that firms place greater weight on common culture for partner selection. 
The fifth paper is a further example of inter-firm risk management, but in the context of project management. Jordan, Jørgensen \& Mitterhofer investigate the use of risk maps in inter-organizational project collaboration in the Norwegian petroleum industry. Jordan et al. show how risk representation technologies such as risk maps come to be seen as 'useful' beyond their conventional role as a technology of risk management. Their study extends and complements existing explanations of the pervasiveness of enterprise risk management technologies and its interrelation with project management and inter-organizational controls. Jordan et al. show how risk maps act as mediating instruments, which allow distributed actors to adjudicate interests, build confidence in and associate with the project and its progress over time. In particular, risk maps play a role in the production of commitment, the creation of the project's identity and act as a platform for mediating concerns between different actor groups in an inter-organizational setting.

In the final paper in this special issue, Plesner Rossing examines the impact of tax strategy on management control systems in a multinational enterprise (MNE) facing transfer pricing tax risks and finds that it is contingent upon the MNE's response to its tax environment. Taking a contingency perspective and applying Simons (1995) 'Levers of Control' framework, Plesner Rossing found that belief systems and interactive control systems are used to reinforce the values upon which the tax strategy is based, and to stimulate learning about the tax environment for transfer pricing practices. Boundary systems and diagnostic control systems are used prescriptively to constrain and guide accepted behaviour, and to ensure monitoring of the arms-length nature of business unit profit margins. Plesner Rossing also illustrated the role of inter-organisational network collaboration across MNE transfer pricing tax experts, a reputation-based selection criterion similar to the finding in the Ding et al. paper.

These papers identify some important themes that move discussion beyond the realms of risk management as yet another kind of formal management control. The role of power and its use by elites (Huber \& Scheytt); how uncertainty creates organizational space for heterogeneity and leads to complex, unresolved and abstract information being pushed to the top of the organization (Tekathen and Dechow). In the inter-firm perspective we can see how risk influences the broader package of practices to manage cooperation between firms in a supply chain relationship (Dekker, Sakaguch \& Kawai); and how partner selection criteria brings in the notion of risk as it enables a more fine-grained analysis of which selection dimension mediates risk on which contract dimensions (Ding, Dekker \& Groot). Linking the idea of power and elites with inter-organizational relationships, risk representation technologies such as risk maps can be seen as 'useful' beyond their conventional role as a technology of risk management (Jordan, Jørgensen \& Mitterhofer); while the role of international experts and the organizational response to its tax environment impacts management controls when facing transfer pricing tax risks (Plesner Rossing). 
The collection of papers in this special issue reveal that organizations and their risk management systems do not exist in a vacuum - they are essentially dynamic entities characterised by power, politics and fear, as well as a desire for organizations to act as if they are in control. Through risk management, organizations are being organized, legalized and made audited (Power 2007). Thus, future research in risk management and how it relates to management accounting and control needs to take account of the wider social, institutional and organizational context in which it operates, rather than just focusing on the technical aspects of risk management. As the papers in this special issue have to some extent demonstrated, risk management is not dissimilar to broader accounting practice and in many ways can be seen as:

"an attempt to intervene, to act upon individuals, entities and processes to transform them and achieve specific ends" (Miller, 2004: 1).

The work of Michael Power $(2004,2007)$ raises a number of issues that are of particular interest for management accounting and control researchers as well as the roles of management accountants. There are two aspects here that are particularly relevant: the side effects of risk management and the relationship between risk management and uncertainty: Power $(2004,2007)$ highlights the 'risks of risk management' and the emergence of 'secondary' or 'defensive' risk management. He suggests that:

"experts who are being made increasingly accountable for what they do are now becoming more preoccupied with managing their own risks"(Power, 2004, p.14).

Power argues that this "culture of defensiveness" (p. 14) can be seen in the 'individualization' of risk by various professionals - whereby, experts are becoming preoccupied with managing their own risk which necessitates reflexive behaviour (Beck, 1992; Giddens, 1990). Further side effects include blame avoidance (Hood, 2002), fear of sanctions, legalization and the re-drawing of (organizational) boundaries that arguably may lead to a re-enforcing of the 'box ticking' culture.

In terms of risk management and uncertainty there have been substantial developments in organizational practice that focus on risk management and issues of governance, but the impact of risk and uncertainty has not been fully explored. Managers have always faced uncertainty - it is a central feature of any organizational setting. Power (2007) argues that when uncertainty is organized, it becomes a risk to be managed. The range of uncertainties deemed in need of management has significantly increased and includes threats such as operational risks, reputational risks and strategic risks. These changes have implications for management accountants in relation to the identification, monitoring, control and mitigation of risk and yet, the discourse of risk and the way it is managed is not always a feature of the wider management control framework in organizations. 
Of particular interest here is the role of management accountants: While we argue that risk management has moved away from being an issue about calculative cultures (Mikes, 2009) to one of management control, where do management accountants fit into this? In the case of UK financial services, Soin and Scheytt (2009) highlight the growing significance of riskbased approaches to the regulation of financial services institutions (since the mid-1990s) and the subsequent diminishing relevance of management accounting systems and the role of management accountants - arguing that the impact of new technologies has reduced the emphasis on cost and enhanced the focus on risk. Baldvinsdottir, Burns, Nørreklit, and Scapens (2010) have documented the changing role of the management accountant and it might be the case that we are entering a new phase of change in relation to risk management practice. Burns and Baldvinsdottir (2005) highlight the emergence of "hybrid accountants' who they found "were becoming involved in wider, integrated business situations, agendas and decision-making forums" (p.749). It might be the case that management accountants start to take a more proactive role in connecting and communicating risk control systems acting as points of reference for knowledge sharing both within and outside the organization.

If, as Power (2004:13) notes, risk management is "part of a new style of organizational discipline and accountability", issues around accountability and responsibility, and outcomes and performance need to be further researched - by linking risk management and control activities to organizational objectives, for example, in the case of ERM systems. Anecdotal evidence suggests that risk management is finding its way into the overall performance measurement systems of banks (although post-financial crisis, the actual value of this can be disputed) and this is familiar territory for management accounting (Williamson, 2004).

One final observation is around the issue of trust. Many of the papers in this special issue, Dekker et al, Ding et al, Huber and Scheytt and Tekathen and Dechow, highlight issues around trust. The issue of trust has been constructed as an alternative to accountability where accountability is undertaken through formal control systems such as risk management. The intention of these systems is to create accountability in order to foster trust. One example is reputation risk where the aim is to create accountability, i.e. external trust. However it is not entirely clear how this impacts on trust between actors inside organizations, how it leads to defensive behavior, fear of sanctions and blame avoidance by organizational actors. This would be one fruitful area for future research.

\section{References}

Agamben, Giorgio. (1998). Homo Sacer: Sovereign Power and Bare Life. Stanford: University Press.

Agamben, Giorgio. (2005). State of Exception. Chicago: University of Chicago Press. 
Arena, M., Arnaboldi, M., \& Azzone, G. (2010). The organizational dynamics of Enterprise Risk Management. Accounting, Organizations and Society, 35(7), 59-675. doi:

10.1016/j.aos.2010.07.003

Ayres, I., \& Braithwaite, J. (1992). Responsive Regulation - Transcending the Deregulation Debate. New York: Oxford University Press.

Baldvinsdottir,G., Burns, J., Nørreklit, H. and Scapens, R. (2010),Professional accounting media: accountants handing over control to the system, Qualitative Research in Accounting \& Management, 7 ( 3) pp. 395- 414

Beck, U. (1992). Risk Society: Towards a New Modernity. London: Sage.

Berry, A.J., Collier, P., \& Helliar, C. (2005). Risk and control: the control of risk and the risk of control. In A. J. Berry, J. Broadbent \& D. Otley (Eds.), Management Control: Theories, Issues and Performance (2nd ed., pp. 279-299). Basingstoke, Hants.: Palgrave Macmillan.

Bhimani, A. (2009). Risk management, corporate governance and management accounting: Emerging interdependencies. Management Accounting Research, 20(1), 2-5. doi: 10.1016/j.mar.2008.11.002

Burns, J. and Baldvinsdottir, G. (2005). An Institutional Perspective of Accountants' New Roles - The Interplay of Contradictions and Praxis, European Accounting Review, 14, (4), pp. 725-757.

Collier, P. M., \& Berry, A. J. (2002). Risk in the process of budgeting. Management Accounting Research, 13(3), 273-297. doi: 10.1006/mare.2002.0190

Collier, P.M., Berry, A.J., \& Burke, G.T. (2007). Risk and Management Accounting: Best Practice Guidelines for Enterprise-wide Internal Control Procedures. Oxford: Elsevier.

Committee of Sponsoring Organizations of the Treadway Commission (COSO) (2004). Enterprise Risk Management - Integrated Framework.

Committee of Sponsoring Organizations of the Treadway Commission (COSO) (2007). Internal Control - Integrated Framework: Guidance on Monitoring Internal Control Systems.

Crouhy, M., Galai, D., \& Mark, R. (2000). A comparative analysis of current credit risk models. Journal of Banking \& Finance, 24(1-2), 59-117. doi: 10.1016/s0378-4266(99)00053-9

Dunne, T.M and Helliar, C.V. (2002), The Ludwig Report: Implications for Corporate Governance. Corporate Governance: The International Journal of Effective Board Performance, 2 (3), 2631.

Financial Reporting Council (2010). The UK Corporate Governance Code. London: FRC.

Giddens, A. (1990), The Consequences of Modernity. Cambridge: Polity.

HEFCE (2001-28). Risk management: a guide to good practice for higher education institutions. 
Hilgartner, S. (1992). 'The Social Construction of Risk Objects: Or, How to Pry Open Networks of Risk', in Short J. and Clarke L. (eds.), 39-53. Organizations, Uncertainties and Risks (1992). Boulder, CO.: Westview Press.

Hood, C. (2002). The Risk Game and the Blame Game. Government and Opposition, 37(1), 15-37. Doi: 10.1111/1477-7053.00085

Huber, C. (2009). Risks and Risk-Based Regulation in Higher Education Institutions. Tertiary Education and Management, 15(2), 83 - 95.

International Organization for Standardization (ISO) (2009). ISO 31000:2009 Risk management Principles and guidelines.

Kasperson, J.X., Kasperson, R., Pidgeon, N.F. and Slovic, P. (2003) The social amplification of risk: assessing fifteen years of research and theory. In N.F. Pidgeon, R.K. Kasperson and P. Slovic (eds.) The Social Amplification of Risk. Cambridge, CUP, pp 13-46.

Langfield-Smith, K. (2008). The relations between transactional characteristics, trust and risk in the start-up phase of a collaborative alliance. Management Accounting Research, 19(4), 344364. doi: 10.1016/j.mar.2008.09.001

McGoun, E. G. (1995). The History of Risk "Measurement". Critical Perspectives on Accounting, 6(6), 511-532. doi: 10.1006/cpac.1995.1047

Mikes, A. (2009). Risk management and calculative cultures. Management Accounting Research, 20(1), 18-40. doi: 10.1016/j.mar.2008.10.005

Mikes, A. (2011). From counting risk to making risk count: Boundary-work in risk management. Accounting, Organizations and Society, In Press, Corrected Proof. doi: 10.1016/j.aos.2011.03.002

Miller, P. (1994). Accounting as a social and institutional practice: an introduction. In A. G. Hopwood \& P. Miller (Eds.), Accounting as social and institutional practice (pp. 1-39). Cambridge: University Press.

Miller, P., Kurunmäki, L., \& O'Leary, T. (2008). Accounting, hybrids and the management of risk. Accounting, Organizations and Society, 33(7-8), 942-967. doi:

Power, M. (2004). The risk management of everything : rethinking the politics of uncertainty. London: Demos.

Power, M. (2007). Organized uncertainty : designing a world of risk management. Oxford ; New York: Oxford University Press.

Power, M., Scheytt, T., Soin, K., \& Sahlin, K. (2009). Reputational Risk as a Logic of Organizing in Late Modernity. Organization Studies (01708406), 30(2/3), 301-324. doi: 10.1177/0170840608101482 
Scheytt, T., Soin, K., Sahlin-Andersson, K., \& Power, M. (2006). Introduction: Organizations, Risk and Regulation. [Article]. Journal of Management Studies, 43(6), 1331-1337. doi: 10.1111/j.14676486.2006.00646.x

Simons, R. (1995) Levers of Control. Boston, MA: Harvard Business School Press.

Soin, K. and Huber, C., (Forthcoming 2013). 'The Sedimentation of an Institution: Changing Governance in UK Financial Services', Journal of Management Inquiry. http://jmi.sagepub.com/content/early/2012/12/21/1056492612467510.abstract

Soin, K and Scheytt, T. (2009) Management Accounting in Financial Services, in The Handbook of Management Accounting Research, edited by Christopher Chapman, Anthony Hopwood and Michael Shields, Elsevier (pp.1385-1395).

Stulz, R. M. (1996). Rethinking Risk Management. Journal of Applied Corporate Finance, 9(3), 8-25. doi: 10.1111/j.1745-6622.1996.tb00295.x

Wahlström, G. (2009). Risk management versus operational action: Basel II in a Swedish context. Management Accounting Research, 20(1), 53-68. doi: 10.1016/j.mar.2008.10.002

Williamson, D. (2004) A Call for Management Accounting and Control Research into Risk Management. Paper presented to the Sixth International Management Control Systems Conference, Edinburgh, July 2004.

Woods, M. (2009). A contingency theory perspective on the risk management control system within Birmingham City Council. Management Accounting Research, 20(1), 69-81. doi: 10.1016/j.mar.2008.10.003 